\title{
FUNCTIONALITY AND PERFORMANCE OF THE GIRL CHILD STUDENT TRANSPORTATION PROGRAM IN
} KANO METROPOLIS

\author{
*Suleiman, D. ${ }^{1}$, Iliyasu, I. S., ${ }^{2}$ \\ Department of Urban and Regional Planning, Kano University of Science and Technology, Wudil, Kaduna, Nigeria. \\ *Corresponding Author's Email: suleiman1068@gmail.com
}

\begin{abstract}
This study evaluates the performance of the Girl Child Student Transportation Program in Kano Metropolis. Data used for this study was obtained through questionnaire administration to the passengers that patronized the Girl Child Student Transportation Program. Purposive sampling technique was employed in the selection of respondents and 235 copies of questionnaire were administered to the respondents and 223 were retrieved and used in the data analysis. The study employed the use of both descriptive and inferential statistical methods of data analysis. The findings showed that $62(53.9 \%)$ of the buses are used for the program are fully functional, $29(25.2 \%)$ of the buses are partially functional and $24(20.9 \%)$ of the buses are grounded. The result of the linear regression analysis revealed with inferential evidence that, only seating capacity has a significant relationship with the patrons' trip frequency out of the various service quality determinants. The paper recommends that the management of the Girl child student transportation program needs to design a frame work that will guide the seating arrangement of the bus service in order to achieve the desire goal of the program.
\end{abstract}

Keywords: Students' Transportation, Academic Performance, Public Schools, Bus Service, Reliability of Operation.

\section{INTRODUCTION}

The provision of a well-planned transportation facility is an important feature of an urbanized society. Urbanization needs to be accompanied by an efficient transportation system in place. Fellesson (2008) maintained that the economic wealth and military power of a people or a nation have been closely tied to efficient methods of transportation. Rivera (2008) has advocated the need for the coordination of the transport system to increase the benefits derivable from the system. It includes planning, procurement, maintenance, operations, and marketing strategies embedded in the transportation system (Mugoro, 2014).

Students' transportation system is seen as an act of transporting children and teenagers to and from schools and school events. School transport can be undertaken by school students themselves (on foot or bicycle or for older students, by car), they may be accompanied by family members or the transport may be organized collectively by the public using buses or taxis (Peter et al., 2012). Students' transportation system using public buses is the safest avenue for students to get to their schools because it was found to be less likely to cause serious injury or death than being driven in a family car, walking and cycling (Gutierrez, 2014).

Olubomehin, (2012) posited that the consequence of large school enrolment in the last two decades has led to an increase in the population of school students in both private and public schools in both developed and developing countries. As such, the need for public transportation of students to school became apparent. Alan (2010) argued that student transportation affects student's health and well-being and issues of safety and health while traveling to school can have an impact on a student's attendance and overall academic performance. Joseph, \& Olatunde, (2010) linked the provision of effective transport facilities for students with academic performance because when efficient transport facilities are in place, students are transported to school in the shortest possible time and with maximum comfort. Transportation options can enable students to attend higher-quality schools that might have been previously inaccessible, and they can allow for participation in enriching before- and after-school activities (Soltani, \& Talebi, 2012). Similarly, Mugoro (2012) observed that the transportation system has significant effects on students' school attendance because some students miss first periods in the morning, escape afternoon sessions as they try to get transport, beg for money and private cars assistance which put them into temptations and the traps of devils.

Kano state is reported to have a secondary school population of not less than 1 million within the metropolis (Odengu, 2015). A significant portion of this population commutes daily from homes to schools. Transportation of students from their homes to schools has faced a lot of problems in Kano state due to poor organization and management. Over the years, some students have lost their lives as a result of the roadside accident, some were seriously injured, others have become perpetual latecomers and others have become victims of several forms of abuse by street muggers while going to school using unorganized means of transport (Odengu, 2015). Additionally, unorganized means of transport is one of the major problem facing students in Kano metropolis due to issues related to the poor road network, location of the bus stop and traveling time of student to reach school (Onyango, 2012). 
The Girl Child Student Transportation Program was developed by the Kano state government in 2012 to ameliorate the problems associated with student transportation especially the female students. The state government in the year 2012 acquired 65 Minibusses, 30 Midi buses and 20 Tata buses making a total of 115 buses from the Urban Development Bank under the Federal Mass Transit Programme which were distributed to public schools in the state under the Girl Child Initiative to address problems facing Girl Child Students Transportation in Kano metropolis (Daily Trust, 2012).

However, most studies on student transportation tend to focus on assessing users satisfaction while neglecting the functionality of the vehicle used to provide the services. This study evaluates both users satisfaction as well as the functionality and performance of the program buses. Similarly, in order to achieve the study aim, record of the buses use for the Girl Child Students Transportation program was obtained from the officials of Kano State Ministry of Education and categorized according to their functionally such as fully functional, partially functional and grounded buses.

\section{DESCRIPTION OF THE STUDY AREA}

The research was carried out in Kano metropolitan area, Kano State within the North West Geopolitical Zone of Nigeria. The area lies between latitudes $11025^{\prime} \mathrm{N}$ to $12047^{\prime} \mathrm{N}$ and longitude 8 o $22^{\prime}$ E to 8 o $39^{\prime}$ E. It covers a total area of $499 \mathrm{~km} 2$ with a population of 2,826,307 million people based on 2006 census (Olofin, 1987). The projected population of 2020 is 4.544 .702 with a national growth rate of $2.5 \%$. The study area is made up of Eight (8) local government areas namely; Dala, Fagge, Gwale, Kano Municipal, Nassarawa, Tarauni, Ungogo and Kumbotso (Fig.1)

The climate of the area is influenced by the movement of the two air masses, the maritime air masses originating over Atlantic Ocean. Consequently, the area is characterized by wet season (May - September) which is characterized by south western maritime winds that carry warm and humid air. The dry season (October - April) is characterized by the tropical dry continental wind (Harmattan) from north. The average temperature is a bit hot, even during the cool Harmattan period the minimum temperature hardly falls below $11 \mathrm{oC}$, whilst the monthly average temperature is not less than $20 \mathrm{o} \mathrm{C}$, whereas during the hot season usually Mid - March to Mid-May, the maximum temperature reading may be as high as $40 \mathrm{o} \mathrm{C}$. The average temperature for these hot months may range between 30o C and 32o C (Falola, 2002).

The relief of the study area can be described under three types occupying three distinct zones, as high lands, the high plains and the low Chad plains. The first two types are parts of the high plains of Hausa land, and the third is a part the Chad plains. The relief is greatly influenced by the geology; the highest elevations, associated with structures, and the lowest with the Chad formation (Falola, 2002).

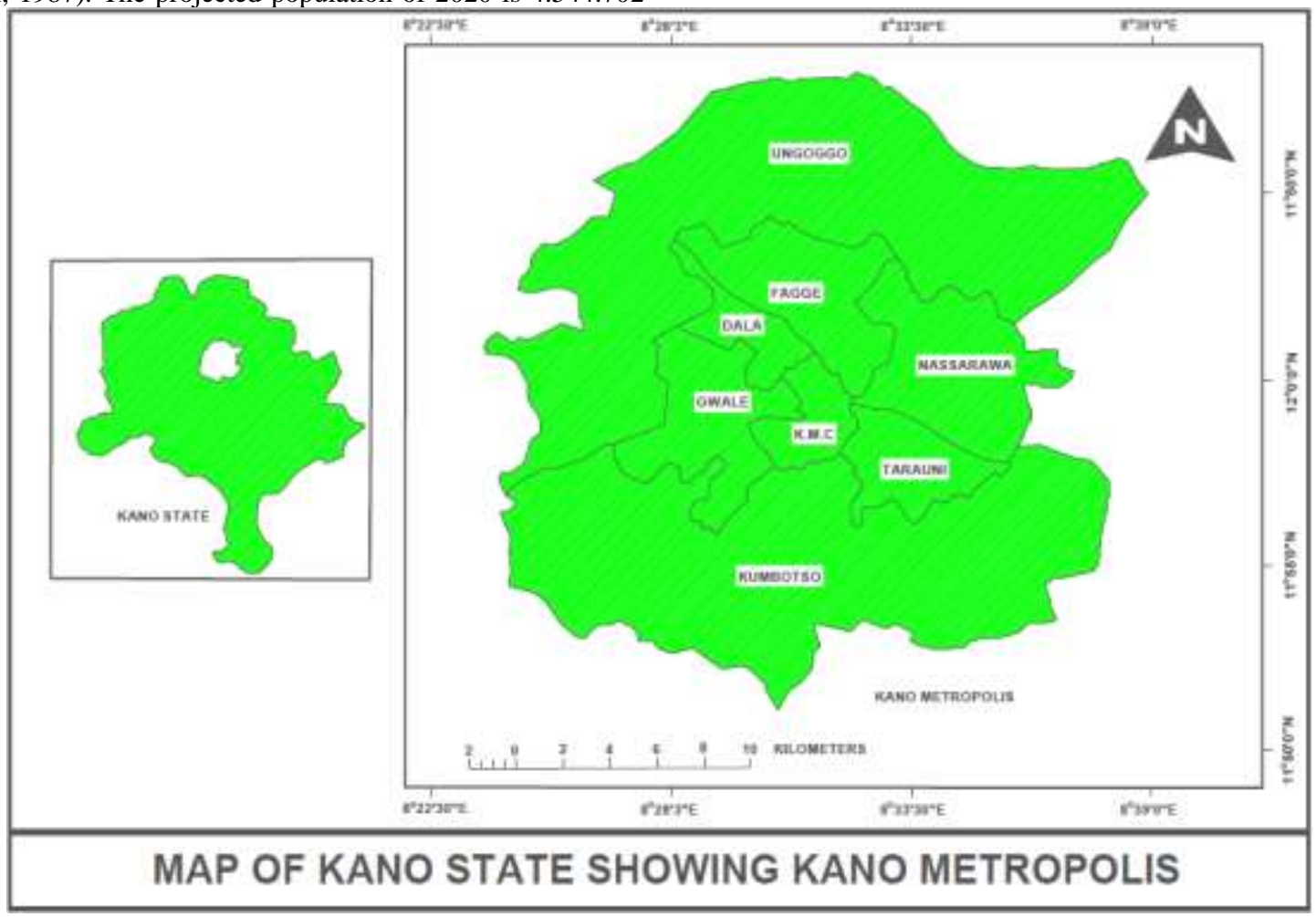

Figure 1: Map of Kano Metropolis 
Source: G.I.S. Lab Geography Department BUK, Kano

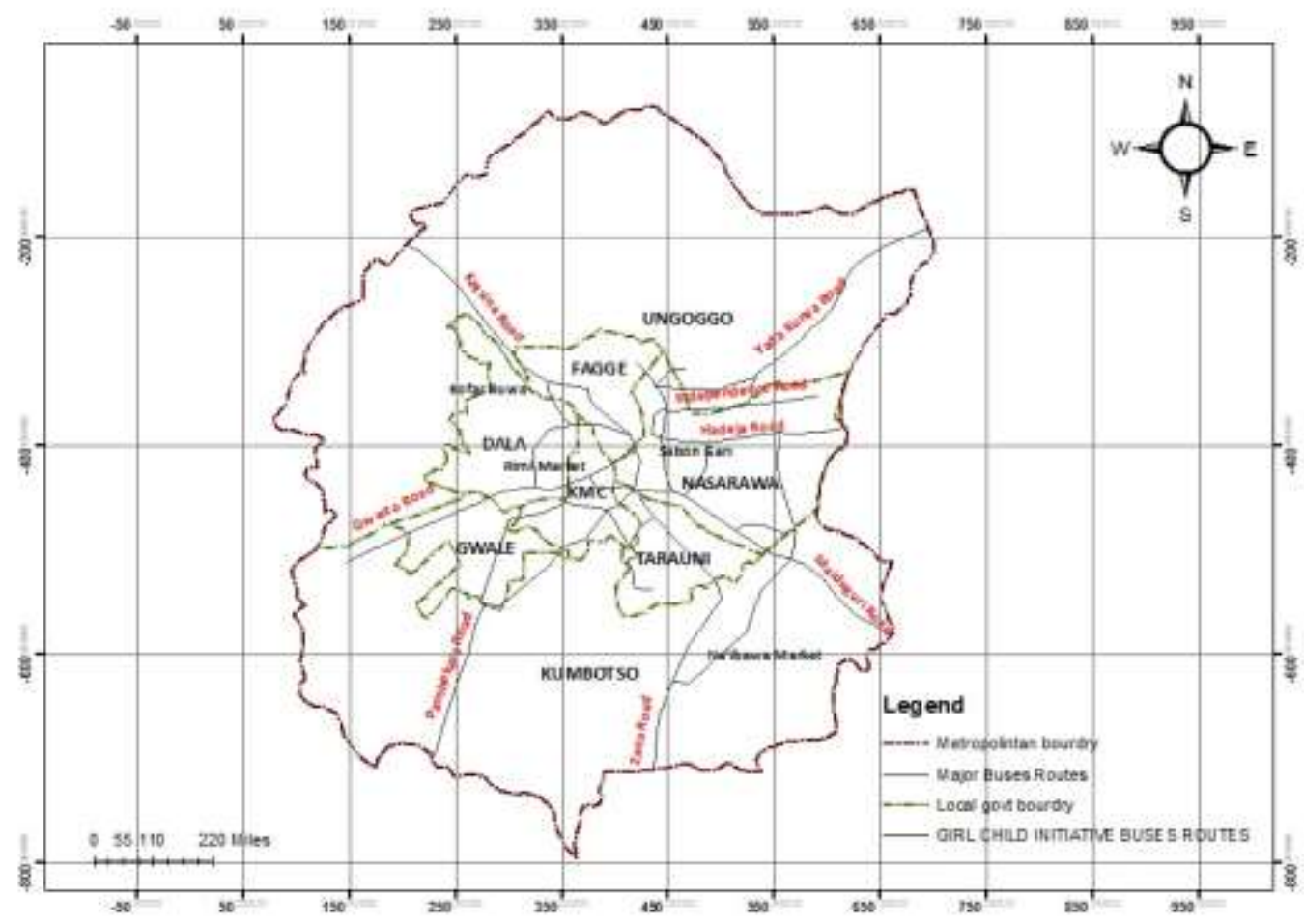

Figure 2: Map of Kano Metropolis Showing Girl Child Initiative Buses Routes Source: G.I.S. Lab Geography Department BUK, Kano

\section{RESEARCH METHODOLOGY}

The data for this study was obtained through questionnaire administration to the users of the program in Kano metropolis to elicit information about their perception with the Girl Child Student Transportation Program. Similarly, a structured interview was conducted with the officials of the Kano State Ministry of Education Board who are in charge of running the program to obtain vital information on the status of the Girl Child Transportation Initiative Buses. The population size for this study was determined based on the average seating capacities of the functional buses used for the program. According to the officials of Kano State Ministry of Education Board, only 91 buses are functional out of 115 total numbers of buses as shown in Table 1. The 91 functional buses have an estimated average seating capacity of 2,530 and this represents the population size of the study. Therefore, Krejcie and Morgan table (1970) was adopted in determining sampling size; where population size of 2530 was represented with 235 sample size and this represents the total number of the questionnaire administered to the respondents. Besides, only 223 questionnaires were duly completed, returned and analyzed which eventually puts the sample size at $94.9 \%$.

Purposive sampling technique is the deliberate choice of an informant due to the qualities the informant possesses (Lyon \& Hardesty 2005; Bernard 2002; Lewis \& Sheppard 2006). Therefore, a purposive sampling technique was used to administered questionnaires to only secondary students that are SS1 and above in the study area. However, both descriptive and inferential analytical tools were used for data analysis in this study. The descriptive analysis includes simple statistical analytical tools like frequency tables while the inferential statistics entails the use of linear regression analysis to explain the relationship between service quality variables (transport fare, seating capacity, reliability and driver handling) and student frequencies of the trip (patronage) using the SPSS package.

Table 1: Number of Buses Used in the Girl Child Initiative Program

\begin{tabular}{lccccc}
\hline Type of Buses & No. of Buses & $\begin{array}{c}\text { Capacity Per Unit } \\
\text { Bus }\end{array}$ & $\begin{array}{c}\text { Seat Capacity } \\
\text { Number of Functional } \\
\text { Buses }\end{array}$ & $\begin{array}{c}\text { Total Capacity of Functional } \\
\text { Buses }\end{array}$ \\
\hline Mini buses & 65 & 18 & 1,170 & 55 & 990 \\
Midi buses & 30 & 30 & 900 & 26 & 780 \\
Tata buses & 20 & 75 & 1875 & 10 & 750 \\
Total & $\mathbf{1 1 5}$ & $\mathbf{1 2 3}$ & $\mathbf{3 , 9 4 5}$ & $\mathbf{9 1}$ & $\mathbf{2 , 5 3 0}$ \\
\hline
\end{tabular}




\section{RESULTS AND DISCUSSION}

Status of the Girl Child Initiative Buses

Based on the existing record and information gathered from the officials of Kano State Ministry of Education about the status of the Girl Child Initiative buses, the status of the buses was categorized according to their functionally such as fully functional, partially functional and grounded buses.

Table 2 reveals the status of the Girl Child Transportation Initiative buses, out of the total 115 buses $62(53.9 \%)$ of the buses used for the program are fully functional. These categories of buses are fully operational with the absence of both major and minor repairs and are fully utilized for the daily conveyance of students of Kano metropolis. Additionally, 29 (25.2\%) of the buses are partially functional requiring some minor attention such as servicing, tyre repairs, replacement of damaged side mirrors, lubricating and greasing, etc. These categories of buses are partially used to convey students to their various schools but not frequently as a result of their uncertainty and unreliability of operation due to poor maintenance culture. Meanwhile, 24 (20.9\%) of the buses are grounded due to major repairs constituting engine failure and spare part related issues. These categories of buses are parked and are not used for the Girl Child Initiative because the ministry in charge cannot handle such magnitude of repairs as a result of lack of funds according to the officials. This infers that the majority of the Girl Child Initiative buses are functional and required minor repairs for better and efficient services to the Girl Child student transportation initiative.

Table 2: Status of the Girl Child Initiative Buses in Kano Metropolis

\begin{tabular}{lcc}
\hline STATUS & NUMBER OF BUSES & PERCENTAGE (\%) \\
\hline Fully Functional & 62 & 53.9 \\
Partially Functional & 29 & 25.2 \\
Grounded & 24 & 20.9 \\
Total & $\mathbf{1 1 5}$ & $\mathbf{1 0 0}$ \\
\hline
\end{tabular}

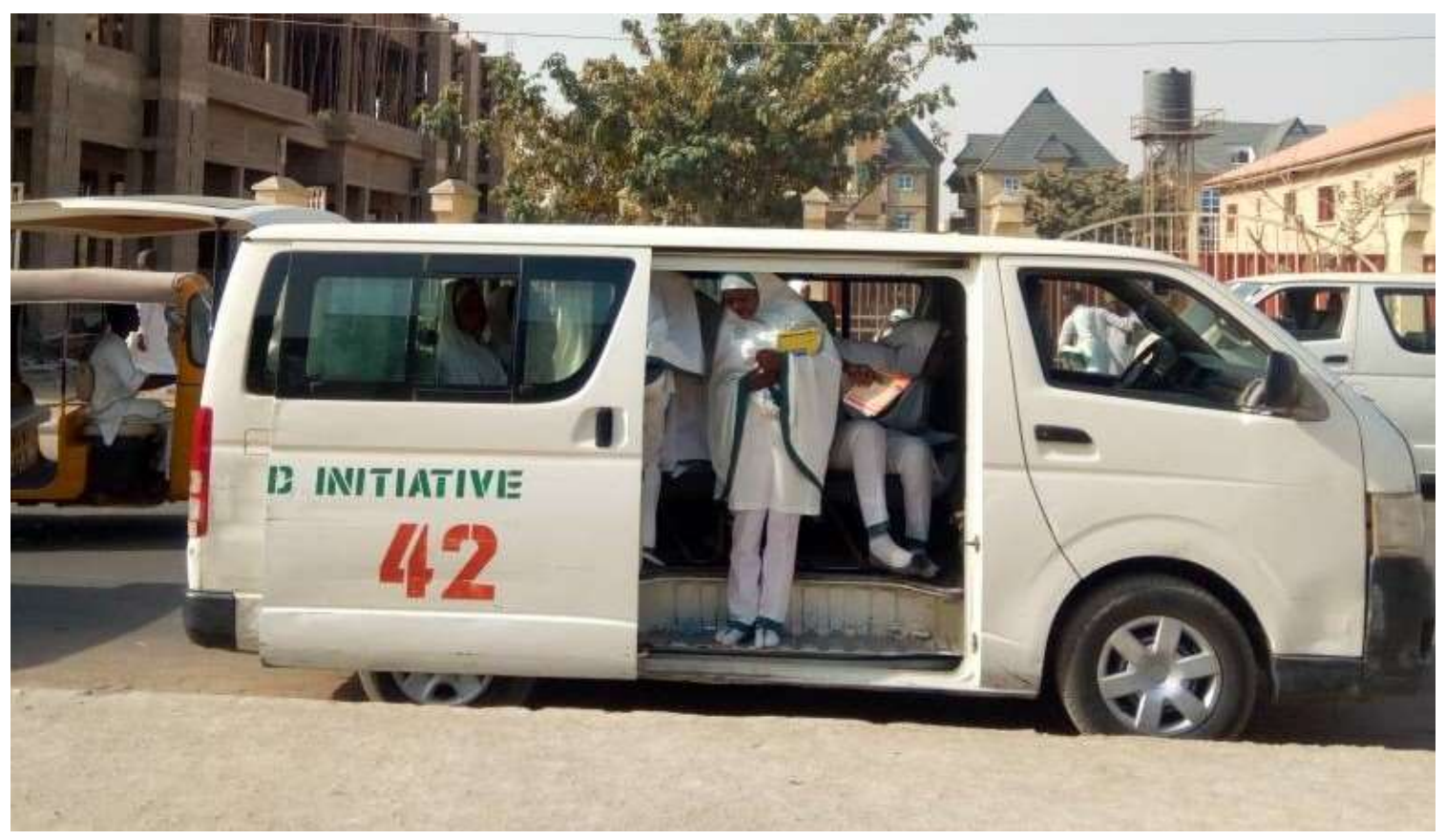

Plate 1: Functional Buses 


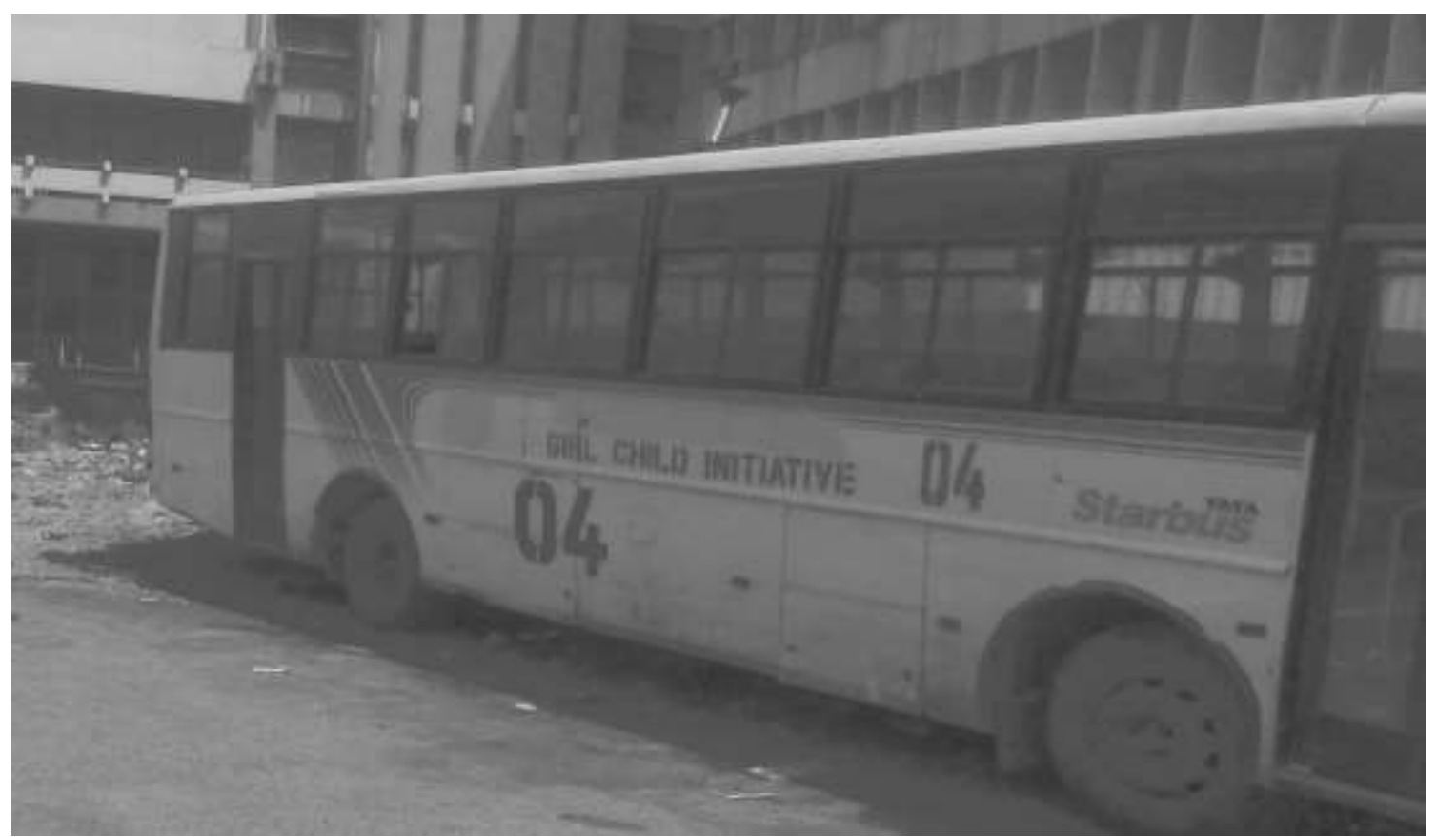

Plate 2: Grounded Bus

Average Usage of Girl Child Students Transportation Buses Table 4 reveals respondents frequencies of usage for the Girl Child Students Transportation buses in Kano metropolis. 108 (48.4\%) of the students patronizes the buses daily, $54(24.2 \%)$ of the students uses the buses at least twice per week, $28(12.6 \%)$ of the students patronizes the Girl Child students buses trice per week, 22 (9.9\%) occasionally and the remaining 11 (4.9\%) uses the Girl Child students buses monthly. This reflected that most of the respondents use the Girl Child students' buses and relied on the Girl Child Students buses for their school transportation.

Table 4: Student Trip Frequencies

\begin{tabular}{lcc}
\hline & Frequency & Percent \\
\hline Daily & 108 & 48.4 \\
Twice per Week & 54 & 24.2 \\
Trice per Week & 28 & 12.6 \\
Monthly & 11 & 4.9 \\
Occasionally & 22 & 9.9 \\
Total & $\mathbf{2 2 3}$ & $\mathbf{1 0 0}$ \\
\hline
\end{tabular}

Factors Influencing the Choice of the Girl Child Students Transportation Buses

The responses of students on their reasons for patronizing the existing girl child initiative buses in Kano metropolis were obtained through questionnaire administration and the responses were based on four (4) major factors of fare affordability, comfort, safety, security and reliability.

Table 3 shows the responses of users on their reasons behind patronizing the Girl Child Students Transportation Initiative buses. $99(44.4 \%)$ of the respondents pointed out that fare affordability is the major reason behind their choices of the Girl Child Students Transportation program. Also, 63 (28.3\%) of the respondents patronize the system due to safety and security reasons. $39(17.5 \%)$ of the respondents patronize the buses because of comfort while the remaining $22(9.9 \%)$ respondents use the Girl Child Students Transportation buses because of the reliability of operations. This reflected that majority of users of the Girl Child Students Transportation program patronizes the buses because of fare affordability especially when compared with commercial buses that charge at least N50 in some cases even N100 depending on the distance of the public school. The Girl Child Students Transportation Initiative Program reduces the burden of student transportation fare to many parents as well as encouraging children's school enrolment especially for parent with many children. 
Table 3: Factors Influencing the Choice of the Girl Child Students Transportation Buses

\begin{tabular}{lcc} 
Reasons & Frequency & Percent \\
\hline Fare Affordability & 99 & 44.4 \\
Comfort & 39 & 17.5 \\
Safety and Security & 63 & 28.3 \\
Reliability & 22 & 9.9 \\
Total & $\mathbf{2 2 3}$ & $\mathbf{1 0 0}$ \\
\hline
\end{tabular}

Level of Satisfaction with the Girl Child Students Transportation Program

The students' level of satisfaction with the Girl Child Students Transportation Program in Kano metropolis was obtained using five (5) service quality attributes of transportation fare, transport cost, reliability, seating capacity and driver handling.

\section{Satisfaction Level with Transportation Fare}

Table 5 shows that 127 (57\%) of the respondents are satisfied with the transportation fare which is N20 per each student and flat rate regardless of distance. Also, $57(25.1 \%)$ of the respondents are highly satisfied with the transportation fare, $29(13 \%)$ are moderately satisfied, $8(3.6 \%)$ of the respondents are moderately satisfied while the remaining $3(1.3 \%)$ of the respondents are highly dissatisfied with the transportation fare. This indicates that most of the respondents are satisfied with the transportation fare.

Table 5: Level of Satisfaction with the Transportation Fare

\begin{tabular}{lll}
\hline & Frequency & Percent \\
\hline Dissatisfied & 8 & 3.6 \\
Highly Dissatisfied & 3 & 1.3 \\
Moderate & 29 & 13 \\
Satisfied & 127 & 57 \\
Highly Satisfied & 56 & 25.1 \\
\hline Total & $\mathbf{2 2 3}$ & $\mathbf{1 0 0}$ \\
\hline
\end{tabular}

Satisfaction Level with Reliability of Operation Table 6 shows the responses of students on the reliability of the buses, $81(36.3 \%)$ of the respondents are satisfied with the reliability of the system, $27(12.1 \%)$ of the respondents are highly satisfied, 59 (26.5\%) are moderately satisfied, 33 (14.8\%) are dissatisfied and the remaining $23(10.3 \%)$ respondents are highly dissatisfied with the reliability of the system. This might be due to buses absconding some times as a result of mechanical fault and other reasons such as fuelling, servicing and tire or spare part problems. This infers that most of the respondents believed the system is reliable.

Table 6: Level of Satisfaction with Reliability of Bus Operation

\begin{tabular}{lcc}
\hline & Frequency & Percent \\
\hline Dissatisfied & 33 & 14.8 \\
Highly dissatisfied & 23 & 10.3 \\
Moderate & 59 & 26.5 \\
Satisfied & 81 & 36.3 \\
Highly Satisfied & 27 & 12.1 \\
Total & $\mathbf{2 2 3}$ & $\mathbf{1 0 0}$ \\
\hline
\end{tabular}

\section{Satisfaction Level with Comfort of Seating Capacity}

Table 7 reveals the level of student's satisfaction with the comfort of seating capacity of the Girl Child buses, 84 (37.7\%) of the respondents are dissatisfied with the comfort of seating capacity, $36(16.1 \%)$ of the respondents are highly dissatisfied, $48(21.5 \%)$ of the respondents are moderately satisfied while only $44(19.7 \%)$ are satisfied and the remaining $11(4.9 \%)$ are highly dissatisfied with the comfort of seating capacity of the Girl Child buses. This might be due to overcrowding as students lap each other leading to squeeze dirt or even tear of student uniform. This reflected that the most of the respondents are dissatisfied with the comfort of seating capacity due to problems relating to seating arrangement and overcrowding. 
Table 7: Level of Satisfaction with Seating Capacity

\begin{tabular}{lcc}
\hline & Frequency & Percent \\
\hline Dissatisfied & 84 & 37.7 \\
Highly dissatisfied & 36 & 16.1 \\
moderate & 48 & 21.5 \\
Satisfied & 44 & 19.7 \\
Highly satisfied & 11 & 4.9 \\
Total & $\mathbf{2 2 3}$ & $\mathbf{1 0 0}$ \\
\hline
\end{tabular}

Satisfaction Level with Driver Handling

Table 8 shows the responses of users on driver handling of the buses, $107(48 \%)$ of the respondents are satisfied with driver handling of the buses, 46 (20.6\%) of the respondents are highly satisfied, $36(16 \%)$ are moderately satisfied, $22(9.9 \%)$ are dissatisfied and the remaining 12 (5.4\%) respondents are highly dissatisfied with driver handling of the buses. This reflected that most of the respondents are satisfied with the driver handling of the buses.

Table 8: Level of Satisfaction with Driver Handling

\begin{tabular}{lcc}
\hline & Frequency & Percent \\
\hline Dissatisfied & 22 & 9.9 \\
Highly dissatisfied & 12 & 5.4 \\
Moderate & 36 & 16.1 \\
Satisfied & 107 & 48 \\
Highly satisfied & 46 & 20.6 \\
\hline Total & $\mathbf{2 2 3}$ & $\mathbf{1 0 0}$ \\
\hline
\end{tabular}

Overall Performance of the Girl Child Students Transportation Program

Based on table 9, $71(31.8 \%)$ respondents rated the overall performance of the program fair, $61(27.4 \%)$ respondents rated the overall performance high, 54 (24.2\%) respondents rated the overall performance low, $20 \quad(9 \%)$ considered the overall performance to be very high and the remaining $17(7.6 \%)$ rated the overall performance very low. This reflected that most of the respondents rated the overall performance of the Girl Child Students Transportation Program fair and high.

\begin{tabular}{lcc} 
Table 9: Overall Performance of the Girl Child Students Transportation Program \\
\hline Performance Level & Frequency & Percent \\
Low & 54 & 24.2 \\
Very Low & 17 & 7.6 \\
Fair & 71 & 31.8 \\
High & 61 & 27.4 \\
Very High & 20 & 9 \\
Total & $\mathbf{2 2 3}$ & $\mathbf{1 0 0}$ \\
\hline
\end{tabular}

\section{Model Summary}

Table 10 shows the adjusted R2 which explained the overall performance of the model. The model shows that $82 \%$ variance (change) in the Girl Child Buses patronage was as a result of combined effect of explanatory variance in the table. However, the remaining $18 \%$ was due to random variable $(\mathrm{R})$ that was captured in the model in explaining the reason why Girl Child Buses patronage increases. This means that Reliability, Transport fare, Seating capacity and Driver handling have a strong relationship with student patronage of the Girl Child Students Transportation Program in Kano metropolis.

Table 10: Model Summary

\begin{tabular}{ccccc}
\hline Model & $\mathbf{R}$ & R Square & Adjusted R Square & Std. Error of the Estimate \\
1 & $.908 \mathrm{a}$ & $\mathbf{0 . 8 2 5}$ & $\mathbf{0 . 8 2 2}$ & 0.551 \\
\hline \multicolumn{2}{c}{ a Predictors: (Constant), Driver handling, Seating Capacity, Transport fare Reliability. }
\end{tabular}

\section{Coefficient}

Based on table 11, standardized coefficients indicate how much the dependent variable varies with an independent variable when all other independent variables are held constant. The beta coefficient indicates that how and to what extent satisfaction with Reliability, Transport fare, Seating Capacity and Driver 
handling influence student patronage. The significant value of Transport fare is 0.382 which is more than 0.05 . This indicates that there has no statistical significant relationship between frequency of trip (patronage) and passenger satisfaction with transport fare. Also, the significant value of Reliability is 0.886 which is more than 0.05 . This indicates that there has no statistical significant relationship between frequency of trip (patronage) and passenger satisfaction with reliability. Additionally, the significant value of Driver handling is 0.003 which is more than 0.05 . This indicates that there has no statistical significant relationship between frequency of trip (patronage) and passenger satisfaction with driver handling. While the significant value of Seating Capacity is 0.000 , which is less than 0.05 , which shows that there is a statistical significant relationship between Seating Capacity and student patronage of the Girl Child student transportation in Kano Metropolis.

Table 11: Coefficient (a)

\begin{tabular}{|c|c|c|c|c|c|c|}
\hline Model & & $\begin{array}{l}\text { Unstandardized } \\
\text { Coefficients }\end{array}$ & & $\begin{array}{l}\text { Standardized } \\
\text { Coefficients }\end{array}$ & $\mathbf{T}$ & Sig. \\
\hline \multirow{6}{*}{1} & & B & $\begin{array}{l}\text { Std. } \\
\text { Error }\end{array}$ & Beta & & \\
\hline & (Constant) & -0.389 & 0.194 & & $-2.002 \mathrm{NS}$ & 0.046 \\
\hline & Transport fare & 0.222 & 0.09 & 0.149 & $2.466 \mathrm{NS}$ & 0.014 \\
\hline & Seating Capacity & 0.862 & 0.057 & 0.858 & $15.152 *$ & 0.000 \\
\hline & Reliability & 0.172 & 0.094 & 0.162 & $1.834 \mathrm{NS}$ & 0.068 \\
\hline & Driver handling & -0.292 & 0.096 & -0.26 & $-3.03 \mathrm{NS}$ & 0.003 \\
\hline
\end{tabular}

\section{CONCLUSION}

This paper has evaluates the performance of the Girl Child Student Transportation Program in Kano metropolis. The paper conclude that among the service quality attributes used in the study, seating capacity recorded the least level of satisfaction which indicates users dissatisfaction with seating arrangement. Similarly, most of the respondents rated the overall performance of the Girl Child Students Transportation Program fair and high. The results of the linear regression analysis showed that only seating capacity has a significant relationship with the patrons' trip frequency out of the various determinants. This implies that the management of the Girl child student transportation program needs to design a frame work that will guide the seating arrangement of the bus service to achieve the desire goal of the program. Additionally, government needs to improve budgetary allocation for the program in order to adequately maintain the buses and avoid having issues related to poor maintenance culture.

\section{REFERENCES}

Alan, T., (2010) “The Cost of Students' Free Ride," IBO Web Blog, Independent Budget Office, January 11, 2010, http://ibo.nyc.ny.us/cgi-park/?p=118.

Bernard, H.R. (2002) Research Methods in Anthropology: Qualitative and quantitative methods. 3rd edition. AltaMira Press ,Walnut Creek, California.

Falola J.A. (2002), Kano. In: Okafor, S., Osaghae E., Ikporukpo, C., and Abumere, S. (Eds) Africa Atlases: Atlas of Nigeria. Les Editions J.A, Paris, France, pp 146-147

Fellesson, M., Friman, M. (2008), "Perceived satisfaction with public transport service in nine European cities", Journal of the Transportation Research Forum, Vol. 47 No.3, pp.93-103.

Guiteeireez, W. (2014). Students Bus Safety Responsibilities and Procedure Guidelines: Paper presented on 28th march, 2014. Berlin Germany
Joseph, O. \& Olatunde, Y.P. (2010). School Location and Academic Achievement. Doctoral dissertation, Kampala International University. Retrieved November 5th, 2017 from http://ccsenet.org/journal/index.php/ass/article/download.

Lewis, J.L. \& S.R.J. Sheppard. 2006. Culture and communication: can landscape visualization improve forest management consultation with indigenous communities? Landscape and Urban Planning 77:291-313.

Lyon, L.M. \& L.H. Hardesty. (2005), Traditional healing in the contemporary life of the Antanosy people of Madagascar. Ethnobotany Research and Applications 3:287-294.

Mugoro, J. (2014). Transportation Problems for Students and Effects on Attendance in Community Secondary Schools Dar es Salaam, Unpublished Masters Dissertation Planning and Policy Studies Department, Open University Tanzania

Olubomehin, O.O (2012) "The Nigerian Motor Transport Since the 1920s", in international Journal of Humanities and Social Sciences, Vol. 2 No. 12

Peter, E., Christopher, L. \& Kazumari, L. (2011). Analysis of Public Transport for School Children. Retrieved November 5, 2017 from www.young scientists.co.tz /.../ Jamhuri_DSM.pdf

Soltani, A. and Talebi, T. (2012), An Investigation of the Spatial Distribution and Location Analysis of Public Bus Terminals of Shiraz using Analytic Network Process (ANP), University Of Isfahan, Urban - Regional Studies and Research Journal, Vol. 5 - No. 18 